\title{
Future Forecasting Wicked Problems: A New Framework For Design
}

\begin{abstract}
Design can be characterized as 'knowledge for future transformation' and is a discipline concerned with developing new products, systems and services that change the future. However, the methods we use for generating foresight are underdeveloped and some gaps and issues remain. This is especially true between more speculative approaches to designing futures and applied industrial approaches. This paper explores these issues in relation to addressing wicked problems in design, specifically the emphasis on qualitative methods and how these lack measurable indicators of problem improvement. The use of mixed methods offers possibilities for combining the power of abductive thinking generating alterative visions of the future alongside quantifiable improvements. We review methods for future forecasting in other fields including economics and business management and explore how these can be transposed into design practice to address some of the issues raised. A proposal is made to achieve this via an interdisciplinary mixed method approach by instigating a process of gap analysis within a new design futures framework.
\end{abstract}

\section{Keywords}

Future Forecasting, Wicked Problems, Design Methods

\section{Introduction}

The argument for future forecasting in design is based on the following semantic difference between 'prediction' and 'forecasting': predicting refers to announcing future events and making prophecies; forecasting is about making calculated hypotheses and suppositions about what could happen in the future using qualitative or quantitative information from the past or present. The importance of thinking about the future and preparing for it has grown in the last decades, due to the increasing awareness and number of complex and undefinable problems. These are issues which cannot be solved with a miraculous solution, simply because the problems are too complex and dynamic for solutions to be proposed before we begin to tackle the problem. Examples of wicked problems include opiate addiction, obesity, climate change, anxiety. Further, we recognize that the issues of climate change are composed of a complex interacting set of wicked problems.

The type of future forecasting we focus on here is specifically aimed towards supporting the improvement of wicked problems tackled via a range of design methods by designers or those trained in design methods from a range of disciplines. These include traditional design fields such as industrial design and service design but also those working in health, energy, social, transport, ICT and other fields. 
Rittel and Webber called these types of issues "wicked problems", in contrast to "tame problems" which can be approached and solved using known analysis paradigms and decision-making processes. A wicked problem is a complex and troubling situation, which refuses to be fenced and described with a unifying definition and requests interdisciplinary solutions [1]. Figure 1 shows a diagram from Rittel's 'The Reasoning of Designers' and is clearly aimed at generating a flow diagram to tackle complex problems. However, the type of information being processed (qualitative/quantitative) is omitted. Buchanan argues that design, is inherently suitable for tackling wicked problems since it has a potentially universal scope, which is inevitably narrowed down into a subject, emerging from the observed issues and problems [2].

\subsection{Designing for the Future}

The field of design is focused on changing the future: two early historical examples are Buckminster Fuller's 1956 course about Comprehensive Anticipatory Design Science, which was aimed at systematically foreseeing future crisis [3] and Papanek's Design for the Real World, which pioneered the field of sustainable design by citing the adverse effects on the environment of designing products [4].

Other established approaches to exploring possible futures are discursive design, fictional design and its extension - speculative design and critical design (SCD). As the name intends, discursive design is aimed at the creation of products - intended in the broadest meaning possible - which aim to facilitate discourse and debate in design practice [5], fictional design creates

Fig. 1. Rittel's flow diagram from the reasoning of designers (Source: Rittel, H. (1988). The Reasoning of Designers, Arbeitspapier zum International Congress on Planning and Design Theory in Boston, August 1987)

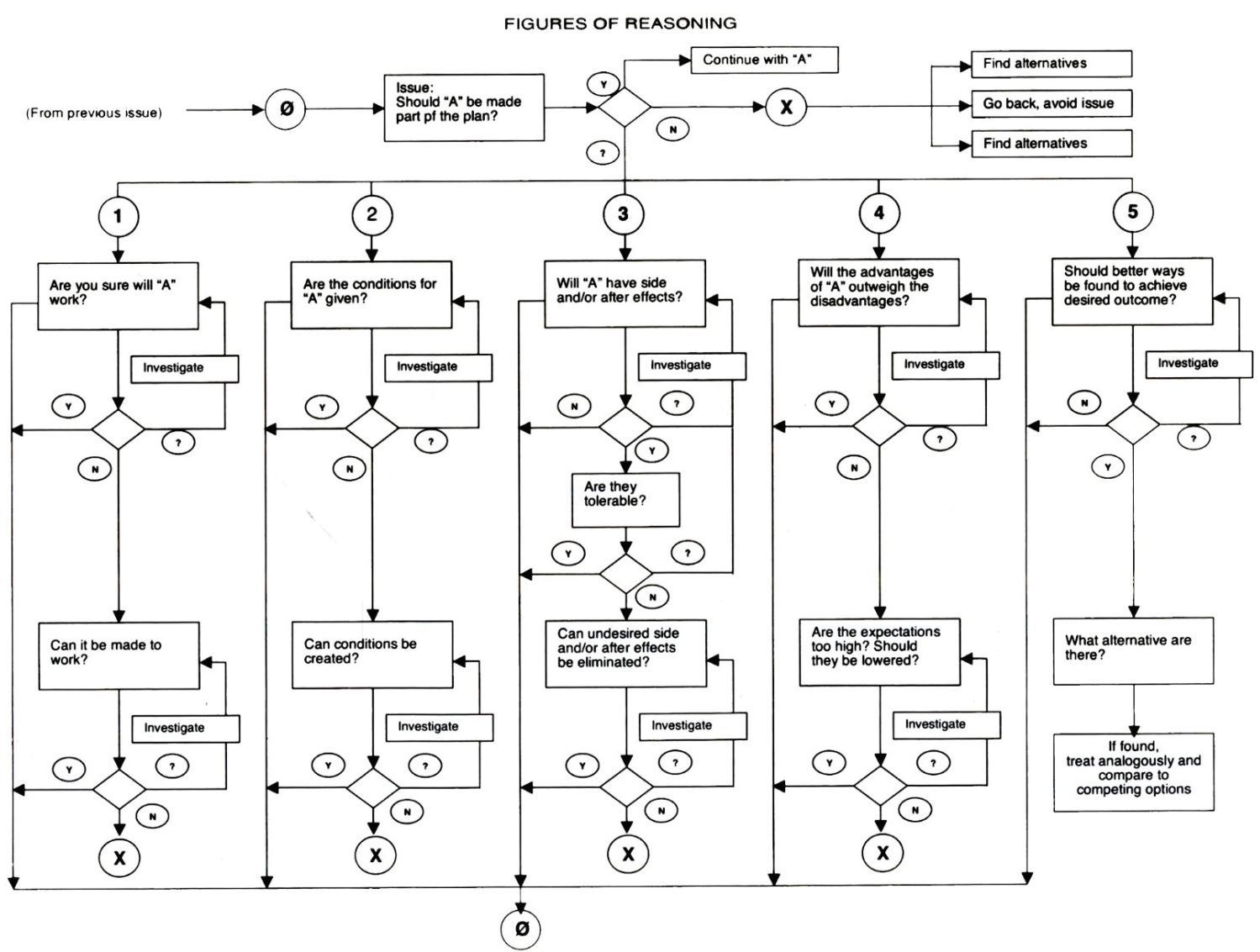


suspension of disbelief through "profitable", "desirable" but not necessarily "buildable" diegetic prototypes [6]. Dunne and Raby [7-9] broadened this second method by framing the prototypes in society and by stressing out their ability to critique the very development of the technologies involved. They use extensively the concept of Future Cones (Figure 2), initially introduced by Hancock and Bezold [10] in 1994 as part of a WHO future of health report and later more commonly referenced by Voros [11], which projects possible, plausible and probable futures and creates an opportunity for constructing a preferable future.

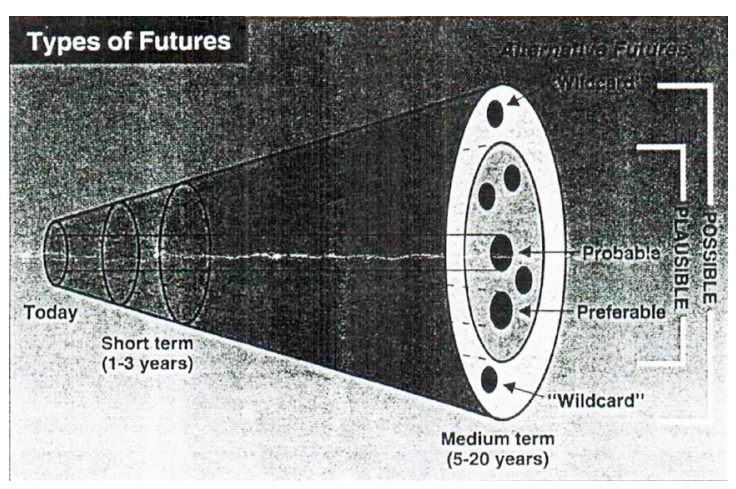

Fig. 2. Futures cone (Source: Bezold, C. and Hancock, T. (1994). An Overview of the Health Futures Field. WHO Consultation, July 19-23.

Although initially conceived as a critique to the over-use of science fiction elements in design, the speculative/ critical approach is grounded in the researcher's previous experiences, rather than the context in which the provocation will take place: two notable examples are the project Foragers by Dunne and Raby [12] and Burton and Nitta's Republic of Salivation [13]. The first was commissioned by the South African organization Design Indaba to explore the future of farming and represents future Caucasian individuals struggling to find food in an over-populated world. As sustainability designer Cameron Tonkinwise imagines in one of his Science Fictions About Critical Design [14], this project might incur some malcontentment if, for example, it would have been exhibited in post-ebola Liberia. In Republic of Salivation, Burton and Nitta envision a future in which food scarcity and hunger is resolved in a centralized and government-led rationing system, which assign nutrients based on the worker's job. Although it resonates with being a possible future dystopia in some European countries, this project would simply be an exercise about recent history in other countries, such as China, Brazil or even post-war Italy.

Another approach that looks at designing for the future specific to the field of $\mathrm{HCl}$ is Reflective Design [15]. Based on Critical Theory, this reflective approach questions the unconscious assumptions in $\mathrm{HCl}$ by outlining a series of principles to be considered when the designer designs interactions with technology. Although these principles can be used to design "better answers" [16] for existing and circumscribed problems, this method does not lend itself to addressing wicked problems.

This fictional and speculative approach to the future, although it may contribute to the creation of stimulating and entertaining narratives in some geographical areas of the world, is rooted in abductive reasoning [17-19], where the designer projects an alternative view of the future world hence creating a difference. It can be argued that the mere act of projection changes the future by offering an alternative that may be adopted. As argued above, wicked problems are fluid issues that cannot be solved with a preemptive solution. Hence, forward-looking yet reductionist design practices, such as discursive, fictional and speculative design, are illequipped when charting a plan of action to tackle them. These future generation methods are aimed at inspiring debate and consciousness-raising for the consideration of the different types of future that we may create. However, they do not claim to solve the issues raised. Speculative critical design deliberately positions itself away from industrial practices and is often exhibited in museum contexts in a situation where feedback loops for tackling wicked problems are weak. Whilst we can see exciting provocative and insightful future projections that often visualize future wicked problem scenarios these leave a significant gap in addressing wicked problems. Improving wicked problems requires the integration of a means to assess the changes that have taken place either by gathering quantitative data or by qualitative assessments throughout the design process.

\section{Research in the fields of economics and business} management has employed extensive forecasting techniques to explore uncertainty in the future and describe the outcomes of decision-making processes [20]. The methods employed rely either on qualitative 
insights or quantitative analysis [21]. It has been demonstrated empirically that either method if employed alone, yields uneven and inconsistent results, but the forecast accuracy greatly increases when the two methods are combined in a meta-forecast [22-23]. In their comprehensive review about the advantages and disadvantages of quantitative and qualitative forecasting methods, Bunn and Wright concluded that the literature on forecasting is overwhelmingly supporting the idea of combining multiple outputs, to increase the forecast's accuracy, its communicability to third parties and its defensibility from criticism [24].

Although some examples of using qualitative and quantitative methods in interdisciplinary teams exist, we found very little focus on over-arching frameworks that are specifically tailored for design-led action in addressing wicked problems using mixed qualitative and quantitative methods throughout the process. We propose to transpose the interdisciplinary integration of intuitive and computational methods common in other fields into the practice of designing for the future through a process of gap analysis, to address wicked problems.

\subsection{Core Assumptions in Future Forecasting}

In order to assist in the development of a framework to integrate qualitative and quantitative methods throughout a wicked problem improvement process we note here a number of assumptions that function to focus our thinking:

1. The ultimate aim of future forecasting is to improve the welfare of humankind, of all animals, plants and the biosphere. This is achieved via the systematic exploration of possible alternative futures: the probable (what is almost sure), the possible (what can be), the plausible (what might be) and the preferable (what ought to be). However, future forecasting is not merely about depicting possible future scenarios: it is the strategic approach on how to reach (or avoid) each one of those scenarios.

2. The future of a wicked problem cannot be stated with absolute certainty. It is inevitable that a certain degree of uncertainty will persist until the forecasted event has passed.

3. Total and organic forecasts are utopic: there will always be some aspects of a problem which were not thought of or deemed essential to address especially as many wicked problems are viewed by diverse stakeholders who may see the problem in very different terms. Furthermore, it is impossible to forecast sudden unexpected impacts and Black Swan events. ${ }^{1}$

4. Interdisciplinary teams, composed of experts in diverse subjects need to work together to produce possible solutions. Lee Fleming demonstrated that in these conditions the outputs, even though not very relevant most of the time, have higher chances of being breakthroughs. For instance, missile guidance systems used by the United States Army in the Sixties were invented during the Second World War by a team composed of Hedy Lamarr (an actor) and George Antheil (an avant-garde composer). Their technology became the precursor to modern radio standards, such as $\mathrm{Wi}-\mathrm{Fi}$ and Bluetooth.

5. Providing forecasts to policy-makers, innovation units and public and private institutions will help them to formulate new social, economic and management policies. These new policies, in turn, will change the future, wearing away the forecast's accuracy.

\section{Compasses and Maps}

Generally, there are two kinds of forecasting methods: qualitative and quantitative [20][25]. The former is sometimes used if there is no data available on the researched topic, or if the data has little or no relevance to the researcher's focus. The latter is used if there is relevant data to assume that events from the past will continue to happen with little variation in the future. When using future forecasting techniques designers overwhelmingly base their methods on qualitative approaches and when data is used it is generally adopted to provide starting points and provide a semblance of rigor from which to base forward looking creative processes. It is much less evident that designers employ data and quantitative methods in partnership with qualitative throughout the wicked problem process in a way that each provides a feedback loop for the other.

\footnotetext{
${ }^{1}$ Term indicating situations and events which appear in a random and unexpected fashion, such as the 2008's financial meltdown and the dot-com bubble in 2001.
} 


\subsection{Qualitative Future Forecasting}

Qualitative future forecasting is based on individual or group creative methods focused on the problems addressed. Due to the high level of experiential individual and group based focus this method is often referred to as 'judgmental' [20]. Inevitably, these methods are leveraged based on an 'expert' focused mindset. Qualitative forecasting is employed when it is deemed that the future will not behave in the same manner as the past. A good example is the Australian Government's decision in 2011 to enforce companies to use dark green on cigarette packaging, in an effort to increase public health by reducing tobacco consumption [26]. Qualitative forecasting is helpful when a large amount of specific and local data is scrutinized to discern patterns which will not be flagged using a quantitative approach, as they require a more nuanced sensibility to be recognized. For example, when a construction company decides which kind of housing it has to build in a specific neighborhood, it generally seeks help from an expert on the local population, to better understand the demographic and cater to their needs. Compared to quantitative forecasting, there are two distinct advantages in using this method:

- It enhances the capacity to anticipate changes in patterns, grounded on the knowledge of experts in the field.

- It gives the flexibility to use both specific, diverse and non-numerical sources, which possibly enhance the forecast's quality since statistics cannot capture all the localized and individual nuances which may be highly significant.

Since this method is rooted in informed opinions and not quantifiable data, there are some caveats, vis-a-vis quantitative methods. A study conducted by Lawrence et al. [27] highlights that the information used in judgmental forecasts are partial and biased to a certain degree, since the data used as a starting point for the analysis is selected without specific criteria and a fixed probability weighting system.

\subsection{Quantitative Future Forecasting}

Quantitative forecasts are often linked to specific disciplines and are developed to address a defined and focused situation but, overall, they can be categorized as
Extrapolative, Explanatory or Simulations.

Extrapolative Methods. These methods assess how the series of observations made until a specific moment in time will continue to evolve in the future. They strictly use information already known to the forecasting team, and do not help in determining what factors can modify or impact the observed course. Consequently, it is possible to extrapolate trends and past seasonal cycles. Usually, extrapolative methods are based on time-series data [28], which are used when trying to forecast an event which is changing dynamically through time [29] such as the stock value of the market.

Explanatory Methods. These methods look at explanatory variables [28], such as the prices of specific goods, and assume that these variables have an explanatory relationship with other independent variables. This model usually includes a third variable, called error, which represents the randomness in the system [28].

Simulation Methods. Simulation methods are based on analogies: a mechanical analogy could be a crash test held to verify a car's behavior in an accident. A mathematical analogy could be an equation describing the behavior of a flock of birds. A metaphorical analogy could be the use of a neural system to describe the working of a computer and a game analogy is used when the player's interactions are symbolic for the interactions inside of society [30].

\subsection{Combining Forecasts}

Combining multiple forecasts deriving from the same method family is a useful procedure to achieve higher accuracy in the overall results [31]. This process of combining results requires an interdisciplinary approach, which leverages on the porous nature of social networks [32] ${ }^{2}$. Ronald Burt [33] argues that the higher the homogeneity of thought in a group, the more access to different points of views and perspective

2 This figure of speech is derived from an interview with former CEO of the French company Rhône-Poulenc: "le vide (literally, the void) has a huge function in organizations. [...] If you do not leave le vide, you have no unexpected things, no creation" [34] [35]. 
the people which are part of multiple groups have, empowering them to have more options to think about and synthesize. They can see more broadly, select data and insights and synthesize them effectively in their practice [34][35].

Combining Qualitative Forecasts. Thus, it is evident that the starting point for an effective forecast is the group of people which constitute the team tackling the issue, the stakeholders involved and their social capital. The complexity lies, therefore, in selecting the appropriate person necessary for the specific context. ${ }^{3}$ Combining various qualitative forecasts can be achieved using various methods, such as the questionnaire-based Delphi, the more visual Futures Wheel or the better known and used Scenario Making. ${ }^{4}$

Combining Quantitative Forecasts. The analysis has to be done in ways that ensure repeatability of the process, such as an arithmetic average. In fact, it has been demonstrated by Robert T. Clement [37] that the simple average can perform as well as more sophisticated statistical methods. The 'magic number' of forecasts to combine has been empirically demonstrated by Makridakis and Winkler [38] when they calculated the error reduction of multiple forecasts combined: most of the error reduction was achieved after combining five different forecasts. A good example of combining forecasts is the work of Lobo and Nair [39]. They analyzed the quarterly earnings forecasts for 96 different companies between 1973 and 1983 , employing two separate qualitative methods and two quantitative extrapolations to justify their projections. By combining the judgmental outputs, they lowered the Mean Absolute Percentage Error (MAPE) by a total of $5.2 \%$ [39].

\section{Future Forecasting for Designers}

Despite the advantages future forecasting offers in terms of risk mitigation, efficient planning strategies and preemptive decision making in the context of economics and business management, the concept has its limitations, as extensively addressed by van Vught [40] and Khan and Mann [41]. The pitfalls of qualitative methods stem from logical fallacies (that is, those which depend on the human factor) and are a byproduct of an underlying fallacy deriving from Hegel's historicist approach [42][43]. His arguments are grounded on inductive reasoning, which states that if it is possible to observe a certain regularity in a limited number of situations, it is feasible to formulate a generic statement which implies the future repetition of that particular instance [44]. This mental framework alone is questionable, as argued by David Hume and Bertrand Russell ${ }^{5}$ [45]: they evidenced the complete lack of any logical argument on which it is possible to base the assurance that future experiences will resemble in any way an already experienced phenomenon. On the other side, an approach to future forecasting which relies solely on computational and quantitative methods can impoverish the design activity by reducing the ability of abductive reasoning to identify alternative futures, in effect it can radically reduce divergent thinking [46]. An improved mental framework for the designer can be suggested by the mixed use of quantitative and qualitative approaches. If quantitative and qualitative research is seen as a continuum, where qualitative-driven research is mainly "constructivistpoststructuralist-critical" and quantitative-driven research is post-positivist [47], the mediation of the two is given by pragmaticist and pluralist approach to the future [48].

To summarize we have argued that traditional design approaches to future forecasting are under-powered in not fully leveraging the capabilities of quantitative methods integrated throughout the creative process of addressing wicked problems. Existing methods from speculative critical design are powerful ways of visualizing alternative futures but have weak feedback loops and were into originally intended to tackle wicked

\footnotetext{
${ }^{3}$ It is important to stress that social capital is not a prerogative of a selected group of people, such as lawyers, scientists or politicians: it lies in those structural holes in the fabric of society, as Burt describes them [38][39].

${ }^{4}$ For a thorough review of qualitative forecasts and how they can be combined, see Glenn \& Gordon's Future Research Methodology [36]. ${ }^{5}$ Russell made evident the fallacy of inductivist reasoning with the famous chicken example: "We know that all these rather crude expectations of uniformity are liable to be misleading. The man who has fed the chicken every day throughout its life at last wrings its neck instead, showing that more refined views as to the uniformity of nature would have been useful to the chicken".
} 


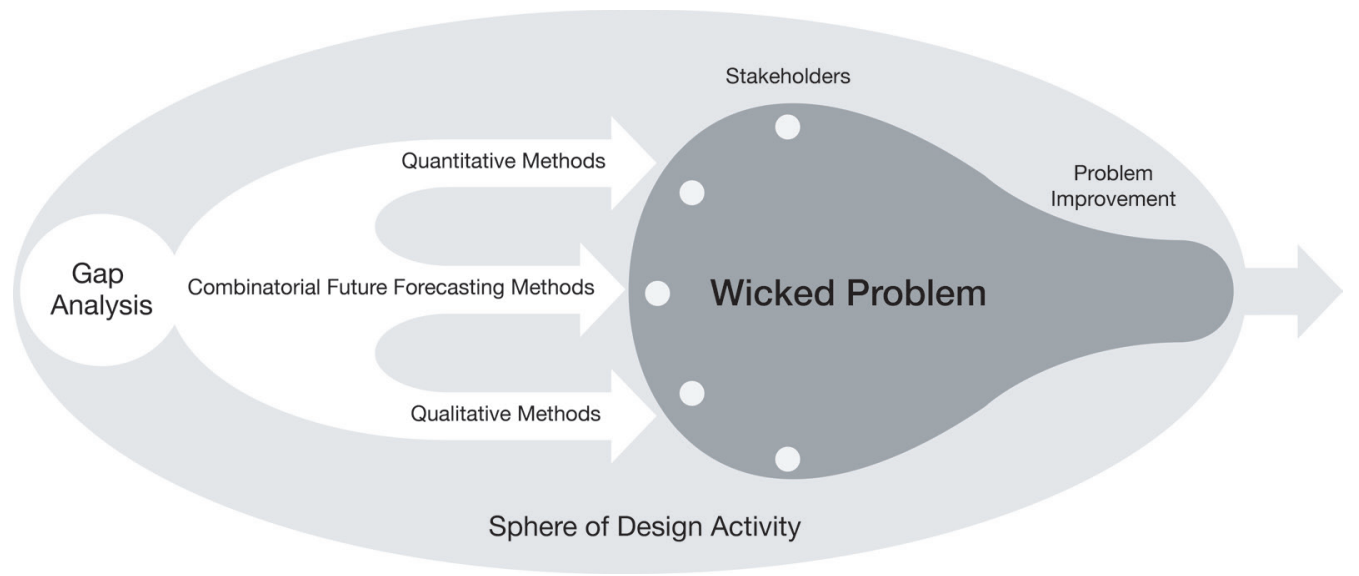

Fig. 3. Diagram illustrating the main interacting elements of the proposed new

design-led future forecast framework for tackling wicked problems.

problem directly.

\subsection{A New Framework}

We propose a new framework for addressing wicked problems using mixed quantitative and qualitative methods leveraging creative design methods. The framework has a number of interacting elements initiated via first identifying a gap in capability for tackling a wicked problem. Gap analysis is a term borrowed from William Burley's research in biological diversity [49]. He defines a gap analysis as a simple concept, which can be described as a continuous loop between:

1. Defining and classifying various elements of biodiversity in a specific area;

2. Examining the preservation systems already present in the territory;

3. Determining which elements are either underrepresented or absent from the initial assessment; 4. Setting guidelines for the next conservational effort [49].

This could be transposed in the design practice by:

1. Defining any number of qualitative future trajectories;

2. Quantitative analysis of datasets and determining trends stemming from it;

3. Determining the discontinuity elements between the two;

4. Setting design principles and constraints for the project.
The diagram in Fig. 3 structures the main elements of the proposed new framework which functions as follows:

The framework proposes an approach to wicked problems from a mixed methods perspective via employing quantitative, qualitative and combinatorial methods to future forecast thereby increasing the forecast's accuracy and its communicability to a variety of involved stakeholders. The synthetic process proposed consists of a gap analysis, where different future trajectories deriving from the different methods employed are mediated by individuating any discrepancies resulting from the different processes. The envisioned design solution or intervention is then steered continuously by the feedback loop given by its own impact on the problem in question via qualitative and quantitative data and insights. This framework is proposed explicitly for designing and wicked problems; therefore, it is intentionally not structured as a series of steps to follow and implement: depending on the problem at hand, the stakeholders included, the available datasets and the level of access to experts in the field, different processes and outcomes are to be expected.

Further research which grounds the framework in a specific wicked problem is needed, so that it can be adapted and tested in a specific instance. 


\section{Conclusion and Future Steps}

Introducing the proposed qualitative-quantitative framework for future forecasting aimed at tackling current and emerging complex challenges seems to be a promising step towards the development of a systematic method for resolving wicked problems. Reflecting back on the definition provided by Rittel and Webber, it becomes clear that the use of mixed techniques of future forecasting could be a desirable method to scan the boundaries of a given problem initiated via a combinatorial strategic design approach. However, since future forecasting is often considered to be an aleatory art without the ability to define the future, its task is not to dictate specific lines of action, but to chart possible outcomes. Therefore, future forecasting as presented in this paper is another method available to the designer to systematically create routes to action.

One of the challenges for our proposed approach is the dominance of qualitative approaches in design and the mistrust, misunderstanding and lack of exposure to the value of quantitative methods. Moreover, many designers consider data driven conclusions that hold central truths to be illusory. While we believe there is significant value to considering this approach, the disciplinary methods preference in design is also a serious consideration. We have also highlighted the inclusion of some cybernetic concepts including feedback loops and there is also potential in further exploration of the relationship between wicked problems and black box technologies and how these problems could be addressed by a new category of mixed methods for future forecasting incorporating qualitative and quantitative feedbacks.

\section{References}

1. Rittel, H. and Webber, M. (1973). Dilemmas in a General Theory of Planning. Policy Sciences, 4(2), 155-169.

2. Buchanan, R. (1992). Wicked Problems in Design Thinking. Design Issues, 8(2), pp.5-21.

3. Fuller, B. (1957). A Comprehensive Anticipatory Design Science. Royal Architectural Institute of Canada, 34, pp.357360.

4. Papanek, V. J. (1984). Design for the real world: Human ecology and social change. New York: Van Nostrand
Reinhold Co.

5. Tharp, B. and Tharp, S. (2019). Discursive Design: Critical, Speculative, and Alternative Things. MIT Press.

6. Sterling, B. (2013). Patently untrue: fleshy defibrillators and synchronised baseball are changing the future. Wired.

7. Dunne, A. (1999). Hertzian Tales: Electronic Products, Aesthetic Experience, and Critical Design. Cambridge: MIT Press.

8. Dunne, A. and Raby, F. (2001). Design Noir: The Secret Life of Electronic Objects. Basel: Birkhauser.

9. Dunne, A. and Raby, F. (2013). Speculative Everything. London: MIT Press.

10. Bezold, C. and Hancock, T. (1994). An Overview of the Health Futures Field. WHO Consultation, July 19-23

11. Voros, J. (2003). A Generic Foresight Process Framework. Foresight, 5(3), pp.10-21.

12. Dunne, A., Raby, F. and Evans, J. (2011). Foragers (part of Between Reality and the Impossible). [Photography] Saint Étienne: Design Biennale.

13. Burton, M. and Nitta, M. (2011). Republic of Salivation (part of After Agri). [Mixed] Den Haag: Stroom.

14. Tonkinwise, C. (2015). Science Fictions About Critical Design. Modes of Criticism, 1, pp.68-75.

15. Sengers, P., Boehner, K., David, S. and Kaye, J. (2005). Reflective design. Proceedings of the 4th decennial conference on Critical computing between sense and sensibility - CC '05.

16. Bowen, S.J. (2007). Beyond "Uncritical" Design. Position paper for Sint-Lucas Research Training Sessions 2007. Hogeschool voor Wetenschap \& Kunst Sint-Lucas, Brussels 14-16 June 2007.

17. Douven, I. (2017) "Abduction", The Stanford Encyclopedia of Philosophy (Summer 2017 Edition), Edward N. Zalta (ed.).

18. Lu, S. and Liu, A. (2012). Abductive reasoning for design synthesis. CIRP Annals, 61(1), pp.143-146.

19. Kolko, J. (2010). Abductive Thinking and Sensemaking: The Drivers of Design Synthesis. Design Issues, 26(1), pp.15-28.

20. Armstrong, J. (2001). Principles of Forecasting: A Handbook for Researchers and Practitioners (International series in operations research \& management science). Springer.

21. Holden, K., Peel, D. and Thompson, J. (1990). Economic Forecasting: An Introduction. Cambridge University Press.

22. Dawes, R. (1986). Forecasting one's own preference. International Journal of Forecasting, 2(1), pp.5-14.

23. Makridakis, S. (1988). Metaforecasting: Ways of improving forecasting accuracy and usefulness. International Journal of Forecasting, 4(3), pp.467-491.

24. Bunn, D., Wright, G., (1991) Interaction of Judgemental 
and Statistical Forecasting Methods: Issues \& Analysis.

Management Science, 37(5):513.

25. Gordon, T. (1992). The Methods of Futures Research. The ANNALS of the American Academy of Political and Social Science, 522(1), 25-35.

26. Australian Government (2011). Tobacco Plain Packaging Act. Retrieved February 25, 2019, from https://www.legislation. gov.au/Details/C2016C00892

27. Lawrence, M. et al. (2006) Judgmental Forecasting: A review of progress over the last 25 years. International Journal of Forecasting. Amsterdam: Elsevier, 22.

28. Makridakis, S. G., Wheelwright, S. C., and Hyndman, R. J. (1998). Forecasting: Methods and Applications. New York: John Wiley \& Sons.

29. Box, G., Jenkins, G., Reinsel, G. and Ljung, G. (2015). Spatial time series. 5 th ed. Wiley.

30. Walonick, D. S. (1993). An Overview of Forecasting Methodologies. 1st ed. Minneapolis, Minn.: StatPac.

31. Doyle, P. and Fenwick, I. A. (1976) Sales forecasting-using a combination of approaches. Long-Range Planning, 9(3), 60 69.

32. Stewart, T. A. (1996). The Great Conundrum: You vs. the Team. New York: Fortune Magazine, 134, 165-166.

33. Burt, R. S. (2004). Structural Holes and Good Ideas. Chicago: The University of Chicago Press, American Journal of Sociology, 110(2), 349-399.

34. Burt, R.S. (1992). Structural Holes: The Social Structure of Competition. Harvard University Press, Cambridge, MA.

35. Burt, R.S. (2000). The network structure of social capital. Research in Organizational Behavior, 22, 345-423.

36. Glenn, J. C., Gordon, T. J. (2009) Futures Research Methodology Version 3.0. The Millennium Project.

37. Clement, R. T. (1989). Combining Forecasts: a Review and Annotated Bibliography. International Journal of Forecasting. Amsterdam: Elsevier, 5(4), 559-583.

38. Makridakis, S. and Winkler, R. L. (1983). Averages of Forecasts: Some Empirical Results. Informs: Management Science 29(9), 987-996.

39. Lobo, J. D. and Nair, R. D. (1990). Combining Judgmental and Statistical Forecasts: an application of Earnings Forecasts.

Decision Sciences. Michigan: Michigan State University, 21, 453-455.

40. van Vught, F. (1987). Pitfalls of forecasting. Futures, 19(2), 184-196.

41. Khan, H. and Mann, I. (1957). Ten Common Pitfalls. United States: RAND Corporation Memorandum.

42. Hegel, G. (1977). The Phenomenology of Spirit. Oxford University Press.
43. Popper, K. (1957). The Poverty of Historicism. Boston: The Beacon Press.

44. Popper, K. (2002). Conjectures and Refutations: The Growth of Scientific Knowledge. New York, London: Basic Books.

45. Russell, B. (2001). The problems of philosophy. 3rd ed. Oxford: Oxford University Press, 19-24.

46. Liddament, T. (1999). The Computationalist Paradigm in Design Research. Design Studies, 20(1), pp.41-56.

47. Johnson, R., Onwuegbuzie, A. and Turner, L. (2007). Toward a Definition of Mixed Methods Research. Journal of Mixed Methods Research, 1(2), pp.112-133.

48. Schoonenboom, J. and Johnson, R. (2017). How to Construct a Mixed Methods Research Design. KZfSS Kölner Zeitschrift für Soziologie und Sozialpsychologie, 69(S2), pp.107-131.

49. Burley, F. W. (1988). Monitoring Biological Diversity for Setting Priorities in Conservation. Biodiversity. Washington: National Academies Press, 227-230. 